\title{
Methods and impact of engagement in research, from theory to practice and back again: early findings from the Patient-Centered Outcomes Research Institute
}

\author{
Laura Forsythe $^{1} \cdot$ Andrea Heckert $^{1} \cdot$ Mary Kay Margolis $^{1} \cdot$ Suzanne Schrandt $^{2}$ • \\ Lori Frank ${ }^{1}$ (1)
}

Accepted: 17 April 2017/Published online: 12 May 2017

(C) The Author(s) 2017. This article is an open access publication

\begin{abstract}
Purpose Since 2012, PCORI has been funding patientcentered comparative effectiveness research with a requirement for engaging patients and other stakeholders in the research, a requirement that is unique among the US funders of clinical research. This paper presents PCORI's evaluation framework for assessing the short- and longterm impacts of engagement; describes engagement in PCORI projects (types of stakeholders engaged, when in the research process they are engaged and how they are engaged, contributions of their engagement); and identifies the effects of engagement on study design, processes, and outcomes selection, as reported by both PCORI-funded investigators and patient and other stakeholder research partners.

Methods Detailed quantitative and qualitative information collected annually from investigators and their partners was analyzed via descriptive statistics and cross-sectional qualitative content and thematic analysis, and compared against the outcomes expected from the evaluation framework and its underlying conceptual model.

Results The data support the role of engaged research partners in refinements to the research questions, selection of interventions to compare, choice of study outcomes and how they are measured, contributions to strategies for recruitment, and ensuring studies are patient-centered.
\end{abstract}

Electronic supplementary material The online version of this article (doi:10.1007/s11136-017-1581-x) contains supplementary material, which is available to authorized users.

Lori Frank

lfrank@pcori.org

1 PCORI, Washington, DC, USA

2 Arthritis Foundation, Atlanta, GA, USA
Conclusions The evaluation framework and the underlying conceptual model are supported by results to date. PCORI will continue to assess the effects of engagement as the funded projects progress toward completion, dissemination, and uptake into clinical decision making.

Keywords Patient engagement - Patient-centered outcomes research $\cdot$ PCORI $\cdot$ CER

\section{Introduction}

Best practice in health-related quality of life (HRQL) assessment evolved to require inclusion of patient input in the development of measures [1], and for many conditions, patient self-report is the standard for assessment of disease and treatment impact [2]. Over the last four decades, the role of the patient in health services research has also expanded. Qualitative and quantitative methods for incorporating the "patient voice" in research are now established [3]. Patients have become increasingly active partners in research, with contributions that extend beyond participation as study subjects. Patient-based advocacy in health research was energized by the ACT-UP movement in the 1980s, changing the norm from investigator-only control of research toward models of shared control. Disability rights activists contributed to this changing research norm through the 1990s, bringing the concept of "nothing about us without us" to public policy and research-based advocacy [4].

The advocacy movement overtly combined political action aims with research, and community-based participatory research emerged as a new model of health research [5]. In the early 2000s, best practice in health outcomes research, which included capturing the patient perspective 
directly from patients, coalesced with the ethos of patient engagement in research in roles beyond that of study participation only. At the same time, the rise of formal health technology assessment (HTA) programs in the UK, Germany, and elsewhere was coupled with a focus on healthcare stakeholder buy-in in the process and outcomes of HTA, leading to new models of inclusion of patients and others involved in health care. During this time, several countries, including the UK, Canada, Germany, France, and Sweden, initiated or expanded patient and public involvement programs [6-10]. While several hallmarks of HTA have been explicitly rejected in the US, patient and stakeholder engagement have been increasingly embraced as worthwhile [10-12]. The establishment of the PatientCentered Outcomes Research Institute (PCORI) in 2010 to fund comparative clinical effectiveness research (CER) energized the focus on engagement of patients and other stakeholders as research partners as a new way of pursuing clinical research. PCORI recognizes that in addition to patients, relevant stakeholder groups include clinicians, hospitals and health systems, industry, training institutions, healthcare purchasers, payers, and policymakers. PCORI's requirement, unique for the large US funders of clinical research, that funded projects engage patients and other stakeholders as partners in the production of the evidence, presents a novel opportunity to address the question of how partner engagement impacts research.

Even in countries in which engagement has been incorporated into health research and HTA for years (for example, Canada, UK), little is known about the specific effects that engaging research partners have on the research process or its outcomes, and collecting this evidence is part of the planning for CIHR and NIHR [13, 14]. The current evidence base is recognized as extremely limited thus far (see for example [15]).We review the evaluation framework developed to guide understanding of PCORI's work and a conceptual model of patient-centered outcomes research (PCOR) [16], and we present quantitative and qualitative findings from the PCORI experience in partnerengaged research to describe engagement in PCORI projects and characterize its effects. Results are compared against the evaluation framework and conceptual model. Implications for ongoing evaluation of engagement in research are presented.

\section{Methods}

\section{Conceptual and practical basis for research engagement questions}

This work was guided by the Evaluation Framework [17], part of PCORI's evaluation plan, developed with input from several groups representing diverse healthcare stakeholders, including the PCORI Board of Governors, Methodology Committee, and Advisory Panel on Patient Engagement. The full framework addresses all aspects of PCORI's work and operationalizes questions about PCORI's work in practice. The section focusing on the impact of engagement in research is the source of the research questions addressed here and is organized into four areas (Fig. 1a):

- description of engagement approaches (who, when, how, etc.), including perceived influence of the research partners and application of the PCOR principles (trust, transparency, honesty, reciprocal relationships, etc.) [16];

- effect of engagement on research processes and intermediate outcomes reflective of studies that matter to patients (e.g., research questions, outcomes selected, study design, dissemination of results);

- longer-term effects of engagement on achievement of PCORI's strategic goals (http://www.pcori.org/aboutus/what-we-do/pcoris-strategic-plan) to increase the quantity and quality of useful information for health decision making, speed uptake of evidence-based information in health decision making, and influence other research to be more patient-centered; and

- impact of engagement in research on better health (health decisions, health care, health outcomes).

The conceptual model of PCOR [16] Fig. 1b specifies foundational elements, actions, and outcomes relevant for patient-centered outcomes research and provides a theoretical foundation for the evaluation framework. The qualitative and quantitative findings presented here provide a check on the accuracy of that model.

\section{Sample and data collection}

From the first funding cycle in December 2012 to June 30, 2016, PCORI funded 434 projects, most for $\$ 3 \mathrm{M}$ each and 3 years, but 11 projects were 3- to 5-year "targeted" projects funded for approximately $\$ 7 \mathrm{M}$ each, and three pragmatic clinical studies were funded for approximately $\$ 12 \mathrm{M}$ each and 5-year duration.

As part of annual project progress reporting, PCORI investigators answer closed- and open-ended questions about their experiences with patient and stakeholder engagement in their PCORI-funded projects. Responses are not anonymous. Data in these analyses are from Year 1 or Year 2 progress reports submitted from July 1, 2015 to June 30, 2016 (reports from the third year of the project are excluded due to small sample size) (Fig. 2). Four projects $(<1.5 \%$ of sample) reported no engagement and were excluded (two projects that did not include engagement in 
a
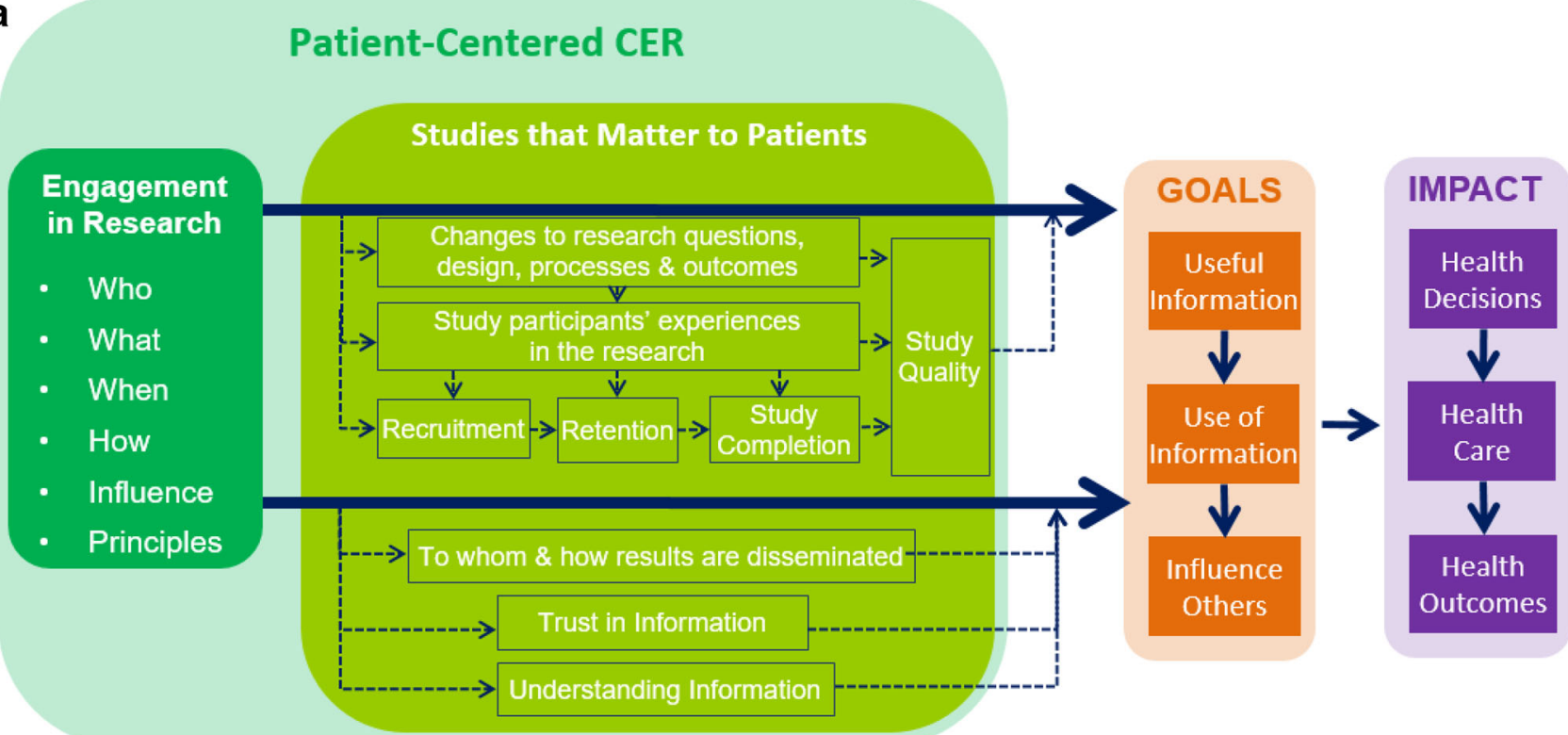

Predictors

Intermediate Outcomes

Long-term Outcomes

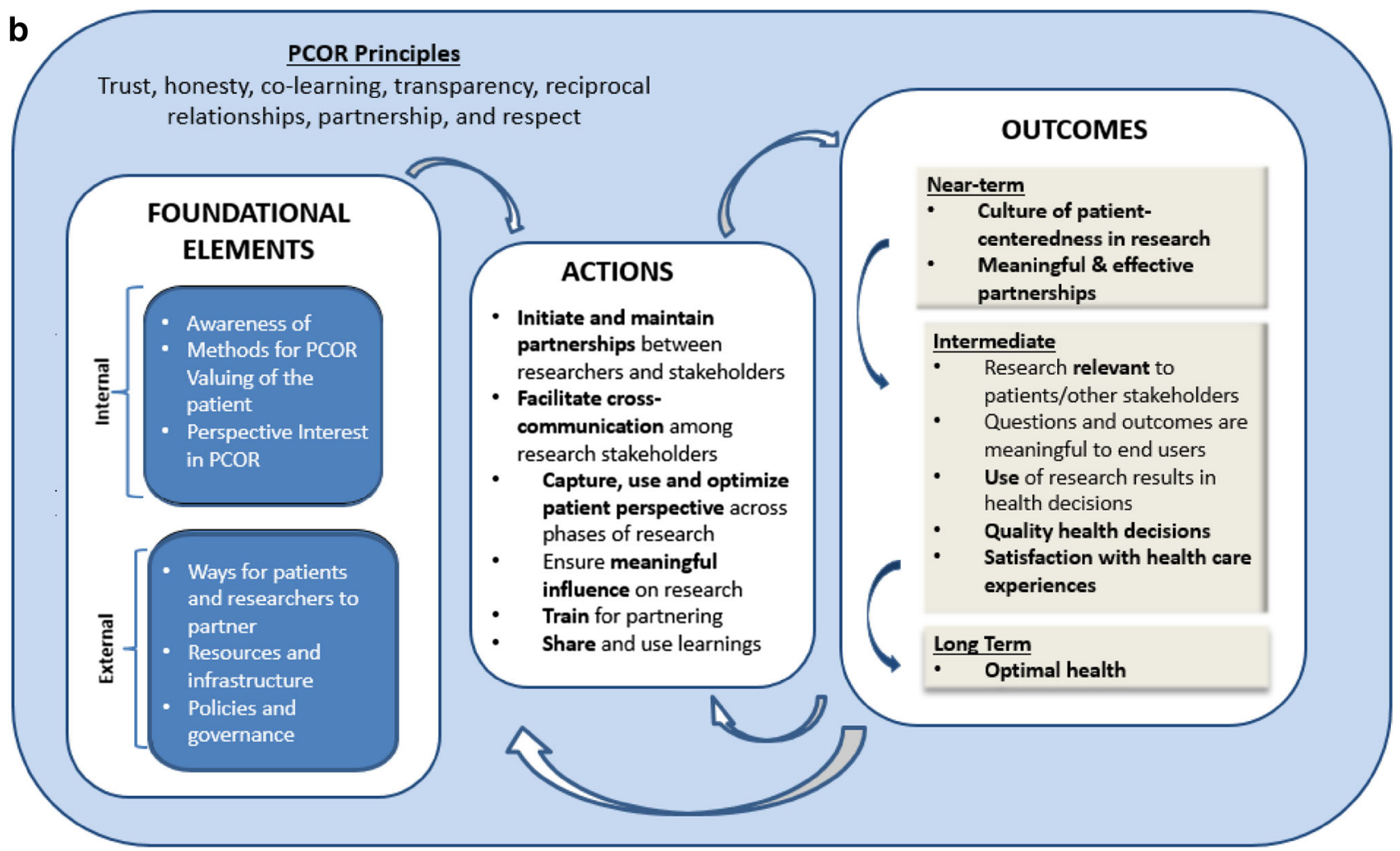

Fig. 1 a PCORI evaluation framework for engagement in research. Note: to view the full evaluation framework regarding all of PCORI's work, see http://www.pcori.org/research-results/evaluating-our-work/ planning-our-evaluation-reporting-results. b Conceptual model of patient-centered outcomes research. Reproduced with permission from Frank et al. [16] 


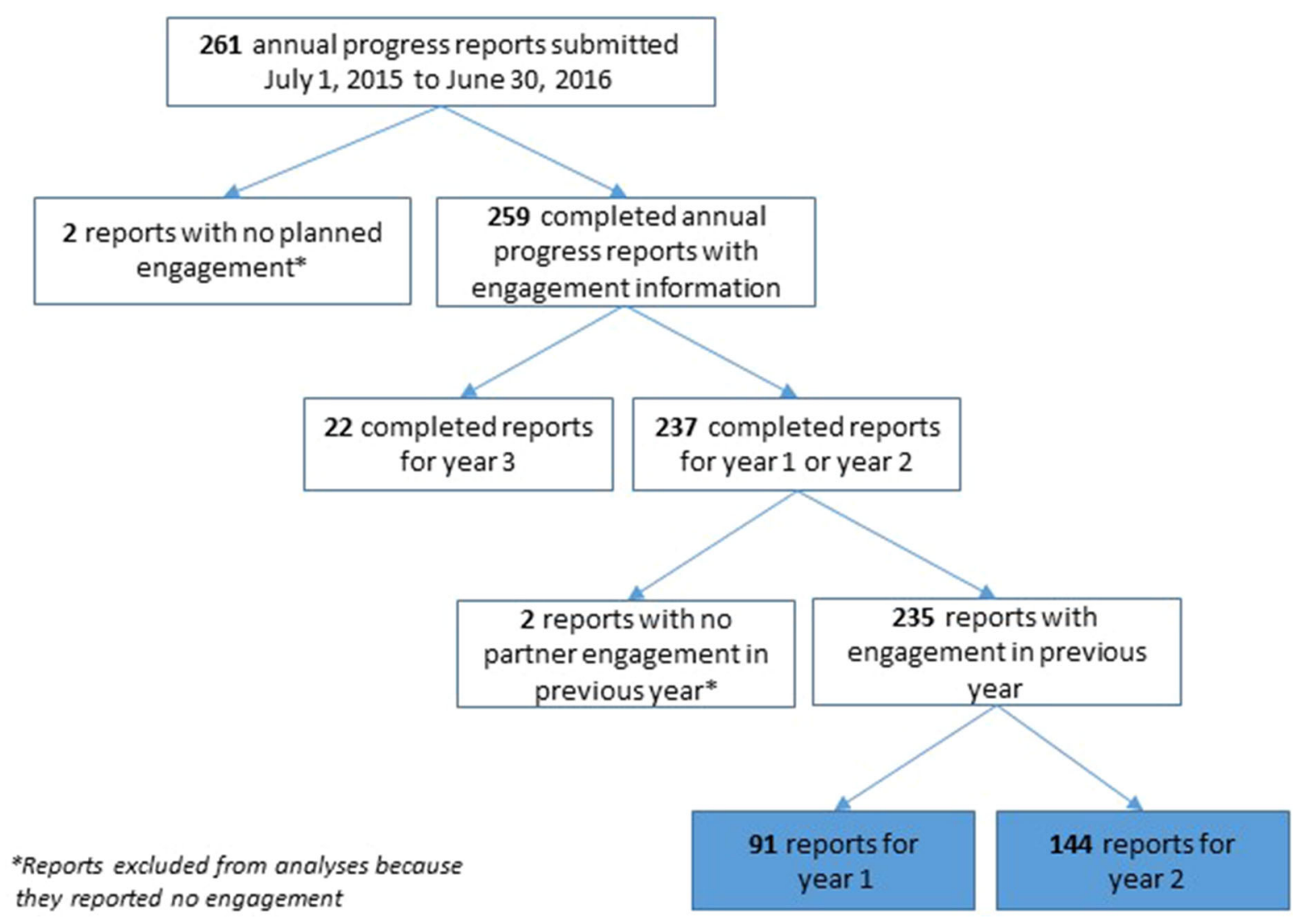

Fig. 2 Investigator report sample

their research plan and two projects that did not engage with partners during the reporting period).

Upon completion of each annual progress report, investigators are asked to nominate up to 10 patient and other stakeholder research partners to provide feedback on their experience with the project. Partners answer closed- and open-ended items about engagement via the Ways of Engaging-Engagement Activity Tool (WE-ENACT), offered via web survey with an option to complete via phone interview. PCORI emails invitations to partners, with up to three e-mail reminders. Data included in the analyses are from partner reports on their engagement in Year 1 or Year 2 of projects, collected from July 1, 2015 to June 30, 2016. Unlike investigator data, research partner completion of the WE-ENACT is voluntary, so the research partner sample represents a smaller pool of funded projects. MaGil Institutional Review Board approved the protocol for collection of information from research partners and for secondary analysis of project or administrative data.

Although more than half (53\%) of the projects in this sample include reports by both the investigators and partners, within-project comparisons between investigators and partners are not made for several reasons. Projects represented in the investigator data may not be represented in the partner data (overall, about two-thirds of investigators nominate partners); partner reporting is voluntary (overall $51 \%$ response rate); and due to the time lag between partner nominations and partner reporting, reports from those nominated near the end of the sampling timeframe may not have been available at the time of this analysis. Multiple partners may report on a single project (range 1-8). Partners report on their individual participation and influence and, while most participate in multiple phases of the project, investigators are responsible for the entirety of the project and report on the contributions of all partners collectively.

\section{Measures}

The closed- and open-ended engagement items of the annual progress report for PCORI investigators and the WE-ENACT for research partners (Appendix A \& B, online) were developed by PCORI staff based on past data collection efforts [18], PCORI's Evaluation Framework [17], a conceptual model of PCOR [16], and the published literature. Over time, changes have been made to both data collection tools based on cognitive testing, feedback from investigators and partners, PCORI needs, and standard survey practices (e.g., retiring items that have reached saturation, resting and rotating items to minimize 
respondent burden, and adding/modifying items to capture new information).

Investigators report on multiple aspects of partner engagement including the communities represented by research partners, the study phases in which partners are engaged, and engagement approaches used. For each study phase with partner engagement, investigators rate the influence of partners (on a 4-point Likert scale from "None" to "A great deal") and complete an open-ended item on partner engagement activities and the effect of these activities ("Describe what patients and/or other stakeholders actually did and any impact this had on the project"). Investigators also quantitatively rate the partner influence on how the team works together and on research projects other than the specific PCORI-funded project.

Each research partner who completes the WE-ENACT reports the primary community he/she represents on the project, the study phases in which he/she has been engaged, and demographic information. For each relevant study phase, the partner is asked to "Describe what you did and how it made a difference."

\section{Analysis}

Cross-sectional analyses were conducted separately for the investigator and partner samples. Closed-ended item responses from investigators were quantitatively analyzed using descriptive statistics (e.g., proportions, means). Openended item responses from both investigators and partners were analyzed via content and thematic analysis [19, 20]. Hierarchical codebooks were developed using deductive (generated through prior work) and inductive approaches (based on the current analytic samples). Codes were applied to relevant text using NVivo v11 software. To ensure coder agreement, three coders independently coded $10 \%$ of the same data and met to reconcile discrepancies. Coded text occurrence queries were generated using NVivo. A frequentist approach to explain the patterns in the data and establish the prominence of themes was deemed appropriate considering the highly structured data collection tools [21]. The minimum threshold for theme identification was $10 \%$ of the relevant responses from both respondent samples. Results are presented separately for the two main aims: description of engagement and characterization of effect of engagement.

\section{Results}

\section{Investigator report sample}

These analyses include 235 reports from investigators: 91 reports on Year 1 and 144 reports on Year 2 (Fig. 2). The projects represent PCORI's five program areas $(n=221$; $94 \%)$, including "targeted" projects $(n=11 ; 5 \%)$ and pragmatic projects $(n=3 ; 1 \%)$. Three quarters of these investigators had 10 or more years of research experience and $52 \%$ were male (Table 1 ). The majority $(96 \%)$ of the investigators were reporting on their first PCORI award;

Table 1 Project reports: investigator characteristics

\begin{tabular}{|c|c|c|c|}
\hline Characteristic & $\begin{array}{l}\text { Year } 1 \text { reports } \\
(n=91)\end{array}$ & $\begin{array}{l}\text { Year } 2 \text { reports } \\
(n=144)\end{array}$ & $\begin{array}{l}\text { Total } \\
(N=235)\end{array}$ \\
\hline \multicolumn{4}{|l|}{ Gender $(n, \%)$} \\
\hline Female & $44(48 \%)$ & $68(47 \%)$ & $112(48 \%)$ \\
\hline Male & $47(52 \%)$ & $76(53 \%)$ & $123(52 \%)$ \\
\hline \multicolumn{4}{|c|}{ Research experience $^{\mathrm{a}}(n, \%)$} \\
\hline $0-4$ years & $7(8 \%)$ & $5(4 \%)$ & $12(5 \%)$ \\
\hline 5-9 years & $16(18 \%)$ & $29(20 \%)$ & $45(19 \%)$ \\
\hline $10+$ years & $68(75 \%)$ & $108(76 \%)$ & $176(76 \%)$ \\
\hline Missing & 0 & 2 & 2 \\
\hline \multicolumn{4}{|c|}{ Previous projects as $\mathrm{PI}^{\mathrm{b}}(n, \%)$} \\
\hline 0 & $3(3 \%)$ & $1(<1 \%)$ & $4(2 \%)$ \\
\hline $1-5$ & $28(31 \%)$ & $53(37 \%)$ & $81(35 \%)$ \\
\hline $6-10$ & $25(27 \%)$ & $27(19 \%)$ & $52(22 \%)$ \\
\hline $11-15$ & $14(15 \%)$ & $16(11 \%)$ & $30(13 \%)$ \\
\hline $16-20$ & $7(8 \%)$ & $14(10 \%)$ & $21(9 \%)$ \\
\hline $21+$ & $14(15 \%)$ & $32(22 \%)$ & $46(20 \%)$ \\
\hline Missing & 0 & 1 & 1 \\
\hline
\end{tabular}

${ }^{a}$ Based on question: How many years of research experience do you have related to this field of research?

b Based on question: Approximately how many grants/contracts have you had funded as the PI or project lead? 
$42 \%$ had previously been principal investigators on more than 10 research studies awarded by other funders.

\section{Partner report sample}

These analyses include 123 reports from Year 1 and 137 reports from Year 2, a total of 260 reports from partners, from 124 different projects, with one to seven partners reporting per project. (mean $2.1 \pm 1.3$ ). Partners in this reporting sample were mostly female $(70 \%)$ and white (78\%), mean age of $54( \pm 13)$ (Table 2). The partners in the projects most commonly represented the patient/consumer $(29 \%)$, caregiver $(12 \%)$, or clinician $(15 \%)$ communities.

\section{Description of engagement}

\section{Quantitative findings}

A majority of the investigators reported engaging with research partners that were patients $(88 \%)$ and/or clinicians (89\%), and more than half reported engaging with clinic or health system representatives $(60 \%)$, patient or caregiver advocacy organizations (57\%), and caregivers (51\%) (Table 3). Investigators reported engaging an average $( \pm \mathrm{SD})$ of $4.9 \pm 2.0$ communities (range 1-11). Common approaches to engaging research partners were via advisory groups $(82 \%)$, and as research team members $(81 \%)$; fewer investigators endorsed using opinion polls/interviews/surveys (39\%). More than half (56\%) of the investigators who reported engaging partners as research team members identified them as engaging at the most active level, as coinvestigators on the project. On average, investigators reported using $2.6 \pm 1.1$ different approaches to engaging partners (range 1-5). Investigators reported that partners were engaged across eight possible study phases (from identifying research topics to disseminating research results; mean $4.9 \pm 1.9$ phases, range $1-9$ when "other" is included). Outcomes and measurement identification were the most common phase with engagement $(75 \%)$. As expected, the proportions of investigators reporting that partners were engaged in the later aspects of a project, including data collection, data analysis/results review, and dissemination were higher for Year 2 reports.

\section{Qualitative findings}

Investigators and partners described a wide range of engagement activities (Table 4). Partners commonly described how they shared personal perspectives in early study phases. These perspectives were grounded in partners' lived experiences (e.g., living with or caring for someone with a health condition among patients and caregiver research partners) and professional expertise (e.g., priorities for clinical care among clinician partners or reimbursement decisions among payer partners), and provided insights on how projects could best address the needs and preferences of the priority patient population(s) and thereby ensure patient-centeredness. For example, one patient/consumer was able to share "how different cultures, genders, and age groups of patients value medical communications and attribute meaning to the end of life" (see Table 4 for additional examples).

Both investigators and partners commonly reported that partners provided guidance and feedback or shared decision making about research questions, design, processes, materials, and outcomes. Across relevant phases, between 20 and $72 \%$ of investigator and partner responses described how partners provided guidance and feedback. Fewer described how partners shared decision making (but exceeded the $10 \%$ theme identification threshold). Both respondent groups also described how partners participated directly in study conduct (from 36 to $77 \%$ of responses in relevant phases). Specifically, partners participated in study participant recruitment (e.g., speaking directly to patients, training research team staff to interact with specific patient groups) and data collection (e.g., conducting interviews, co-facilitating focus groups, administering surveys to study participants, tracking study participant visits). Despite none of the projects being complete yet, investigators and partners reported partner involvement in dissemination activities (e.g., co-presenting at scientific meetings, developing manuscripts, determining avenues to share findings, writing newsletters, participating in media interviews, speaking with public health officials about the project).

\section{Effects of partner engagement}

\section{Quantitative findings}

Investigators indicated that research partners exerted influence in multiple ways, with more than two-thirds indicating at least a moderate influence (Fig. 3). Most investigators $(73 \%)$ indicated that partners had a moderate or great deal of influence on how the team works together. More investigators noted influence at Year 2 relative to Year 1 on research projects beyond the current PCORIfunded (53 vs. $34 \%$ rating of moderate or greater influence, $\left(x^{2}=8.08, p<0.01\right)$.

\section{Qualitative findings}

As a result of partner engagement, multiple aspects of the projects were refined and made more patient-centered (Table 5). Across relevant phases, between 11 and 52\% of investigator and partner responses described enhanced patient-centeredness of study processes and outcomes, and 
Table 2 Project reports: partner characteristics

\begin{tabular}{|c|c|c|c|}
\hline Characteristics & $\begin{array}{l}\text { Year } 1 \text { reports } \\
(n=123)\end{array}$ & $\begin{array}{l}\text { Year } 2 \text { reports } \\
(n=137)\end{array}$ & Total $(N=260)$ \\
\hline Age (mean \pm SD years) & $55( \pm 13)(n=115)$ & $54( \pm 13)(n=128)$ & $54( \pm 13)(n=243)$ \\
\hline \multicolumn{4}{|l|}{ Gender $(n, \%)$} \\
\hline Female & $79(68 \%)$ & $96(73 \%)$ & $175(70 \%)$ \\
\hline Male & $37(32 \%)$ & $36(27 \%)$ & $73(29 \%)$ \\
\hline Transgender & $1(<1 \%)$ & $0(0 \%)$ & $1(<1 \%)$ \\
\hline Missing & 6 & 5 & 11 \\
\hline \multicolumn{4}{|l|}{ Race $(n, \%)$} \\
\hline American Indian/Alaska Native & $0(0 \%)$ & $3(2 \%)$ & $3(1 \%)$ \\
\hline Asian & $4(3 \%)$ & $5(4 \%)$ & $9(4 \%)$ \\
\hline Black or African American & $12(10 \%)$ & $20(15 \%)$ & $32(13 \%)$ \\
\hline Native Hawaiian or other Pacific Islander & $1(<1 \%)$ & $1(<1 \%)$ & $2(<1 \%)$ \\
\hline White & $95(80 \%)$ & $98(75 \%)$ & $193(78 \%)$ \\
\hline Other & $7(6 \%)$ & $3(2 \%)$ & $10(4 \%)$ \\
\hline Missing & 4 & 7 & 11 \\
\hline Ethnicity ( $n, \%$ Hispanic/Latino) & $7(6 \%)(n=118)$ & $5(4 \%)(n=131)$ & $12(5 \%)(n=249)$ \\
\hline \multicolumn{4}{|l|}{ Primary partner community represented $(n, \%)$} \\
\hline Patient/consumer & $35(32 \%)$ & $37(28 \%)$ & $72(29 \%)$ \\
\hline Clinician & $18(16 \%)$ & $14(11 \%)$ & $32(13 \%)$ \\
\hline Caregiver/family member of patient & $12(11 \%)$ & $18(14 \%)$ & $30(12 \%)$ \\
\hline Patient/caregiver advocacy organization & $17(16 \%)$ & $7(5 \%)$ & $24(10 \%)$ \\
\hline Community-based organization & $5(5 \%)$ & $12(9 \%)$ & $17(7 \%)$ \\
\hline Subject matter expert & $7(6 \%)$ & $8(6 \%)$ & $15(6 \%)$ \\
\hline Clinic/hospital/health System representative & $5(5 \%)$ & $7(5 \%)$ & $12(5 \%)$ \\
\hline Payer (public or private insurance) & $0(0 \%)$ & $4(3 \%)$ & $4(2 \%)$ \\
\hline Policy maker (government official) & $0(0 \%)$ & $2(2 \%)$ & $2(<1 \%)$ \\
\hline Other $^{\mathrm{a}}$ & $11(10 \%)$ & $23(17 \%)$ & $34(14 \%)$ \\
\hline Missing & 14 & 5 & 18 \\
\hline \multicolumn{4}{|l|}{ Educational attainment $(n, \%)$} \\
\hline Less than high school & $0(0 \%)$ & $1(<1 \%)$ & $1(<1 \%)$ \\
\hline High school graduate or GED & $2(2 \%)$ & $3(2 \%)$ & $5(2 \%)$ \\
\hline Post high school training other than college (vocational or technical) & $3(3 \%)$ & $4(3 \%)$ & $7(3 \%)$ \\
\hline Some college & $16(13 \%)$ & $25(19 \%)$ & $41(16 \%)$ \\
\hline College graduate & $28(23 \%)$ & $31(23 \%)$ & $59(23 \%)$ \\
\hline Postgraduate & $71(59 \%)$ & $69(52 \%)$ & $140(55 \%)$ \\
\hline Missing & 3 & 4 & 7 \\
\hline Previously partnered on other research project ${ }^{\mathrm{b}}$ ( $n, \%$ yes) & $64(54 \%)(n=119)$ & & \\
\hline Previously partnered with current investigators ${ }^{\mathrm{b}}$ ( $n, \%$ yes) & $46(42 \%)(n=109)$ & & \\
\hline Time worked with current investigators ${ }^{\mathrm{b}, \mathrm{c}}$ (mean $\pm \mathrm{SD}$ ) & $4.3( \pm 3.0)(n=45)$ & & \\
\hline \multicolumn{4}{|l|}{ Study phase(s) in which engaged } \\
\hline Researcher understanding of patient and stakeholder needs & $96(86 \%)$ & $102(77 \%)$ & $198(81 \%)$ \\
\hline Research topics and/or research questions & $43(38 \%)$ & $37(28 \%)$ & $80(33 \%)$ \\
\hline Interventions and/or comparators & $44(39 \%)$ & $34(26 \%)$ & $77(32 \%)$ \\
\hline Outcomes and/or measurement & $62(55 \%)$ & $56(42 \%)$ & $118(48 \%)$ \\
\hline $\begin{array}{l}\text { Recruitment: Training research staff on how to recruit and work with } \\
\text { patients }\end{array}$ & $35(31 \%)$ & $23(17 \%)$ & $58(24 \%)$ \\
\hline Recruitment and retention: Finding and/or retaining participants & $49(44 \%)$ & $43(33 \%)$ & $92(38 \%)$ \\
\hline Data collection & $23(21 \%)$ & $20(15 \%)$ & $43(17 \%)$ \\
\hline
\end{tabular}


Table 2 continued

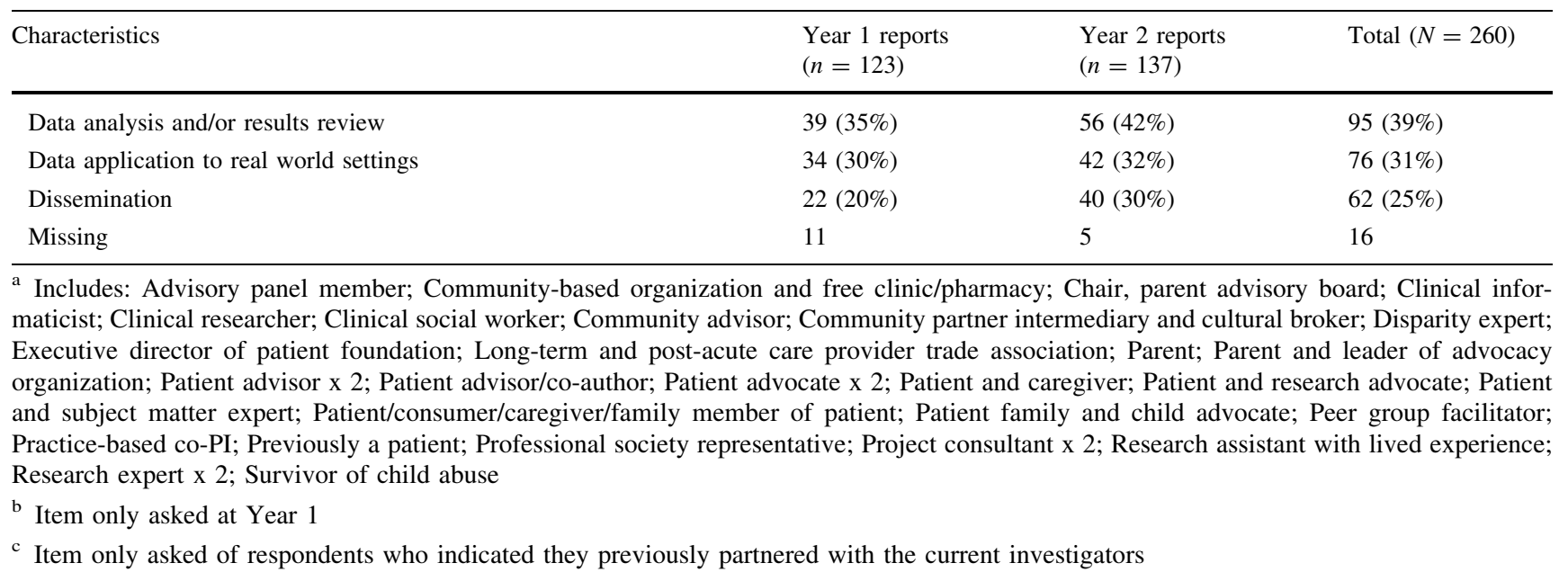

20-81\% described enhanced study design, conduct, or efficiency. As described below, research partners had an impact on selection of research topics and/or research questions, interventions and/or comparators, and outcomes and/or measures used. Both investigators and research partners describe participant recruitment and retention and data collection as more efficient as a result of partner engagement. Although few projects in this sample were nearing completion, there is evidence of research partner influence on affecting data analysis and/or results review and dissemination of study results. These qualitative findings correspond to the investigators' quantitative report of influence of research partners across study phases (Fig. 3).

Both investigators and partners reported that partner input confirmed the importance of research topics they were pursuing, inspired pursuit of specific research questions, and/or refined the research questions to be relevant and aligned with patient or other stakeholders' priorities. For example, one patient/consumer noted "Anxiety became a study topic when it had not been considered before" (see Table 5 for additional examples). Partners also contributed to refining interventions and/or comparators to be more patient-centered, adapting materials or interventions to be culturally/linguistically appropriate, and modifying the intervention to be less burdensome to participants. Partner contributions to outcomes and/or measurement phase include selection of specific primary and secondary outcomes that matter to patients and other information users, and identification and/or refinement of measures of these constructs. Partners often noted that outcomes of interest to them would have been otherwise overlooked and remained unmeasured.

Investigators and partners reported changes to recruitment strategies such as adding or changing recruitment locations, refining inclusion/exclusion criteria, and use of culturally appropriate ways to recruit specific populations. Partner input shaped materials and consent forms (e.g., streamlining, adding more information about risks and benefits). Partners also contributed to participant retention through guidance on the best ways to communicate and suggesting new modes of data collection. Both investigators and partners recognized that partner input contributes to greater perceived value of trial participation among enrolled patients/caregivers, enhanced enrolment rates, and/or improved retention throughout project follow-up periods. Effects of partner contributions on data collection include selection of specific modes of data collection (e.g., electronic vs. phone), informed decisions about timing such as the appropriate follow-up periods, changes as part of clinic work flow, and increased sensitivity around data collection (e.g., insights on why racial/ethnic minorities may be hesitant to share personal information).

While these projects are not complete, early signals indicate effects of engagement on data analysis and/or results review, dissemination, new ways to share results, new audiences to reach, improved communication with different audiences, and increasing credibility of the findings.

\section{Discussion}

PCORI's requirement that awardees engage patients and/or other stakeholders as partners in the research it funds presents a unique opportunity to describe engagement in research as it is implemented across a large portfolio of CER. PCORI's effort to understand engagement in research is a unique, systematic data collection initiative, 
Table 3 Characteristics of engagement in research (investigator-reported)

\begin{tabular}{|c|c|c|c|}
\hline & $\begin{array}{l}\text { Year } 1 \text { reports } \\
(n=91)\end{array}$ & $\begin{array}{l}\text { Year } 2 \text { reports } \\
(n=144)\end{array}$ & $\begin{array}{l}\text { Total } \\
(N=235)\end{array}$ \\
\hline \multicolumn{4}{|l|}{ Partner communities engaged ${ }^{\mathrm{a}}$} \\
\hline Clinician & $83(91 \%)$ & $126(88 \%)$ & $209(89 \%)$ \\
\hline Patient/consumer & $82(90 \%)$ & $125(87 \%)$ & $207(88 \%)$ \\
\hline Patient/caregiver advocacy organization & $56(62 \%)$ & $84(58 \%)$ & $140(60 \%)$ \\
\hline Clinic/hospital/health System representative & $53(58 \%)$ & $81(56 \%)$ & $134(57 \%)$ \\
\hline Caregiver/family member of patient & $43(47 \%)$ & $77(53 \%)$ & $120(51 \%)$ \\
\hline Subject matter expert & $43(47 \%)$ & $78(54 \%)$ & $121(51 \%)$ \\
\hline $\begin{array}{l}\text { Training Institution representative (non-research health professions } \\
\text { educator) }\end{array}$ & $15(16 \%)$ & $22(15 \%)$ & $37(16 \%)$ \\
\hline Policy maker (government official) & $10(11 \%)$ & $28(19 \%)$ & $38(16 \%)$ \\
\hline Payer (public or private insurance) & $13(14 \%)$ & $22(15 \%)$ & $35(15 \%)$ \\
\hline Life sciences industry representative & $2(2 \%)$ & $9(6 \%)$ & $11(5 \%)$ \\
\hline Purchaser (small or large employers) & $0(0 \%)$ & $5(3 \%)$ & $5(2 \%)$ \\
\hline Other $^{\mathrm{b}}$ & $26(29 \%)$ & $68(47 \%)$ & $94(40 \%)$ \\
\hline \multicolumn{4}{|l|}{ Approaches to engaging partners ${ }^{\mathrm{a}}(n, \%)$} \\
\hline Patient/stakeholder research team members & $74(81 \%)$ & $118(82 \%)$ & $192(82 \%)$ \\
\hline Team members as co-investigators ${ }^{\mathrm{c}}$ & $44(59 \%)$ & $63(53 \%)$ & $107(56 \%)$ \\
\hline Advisory groups & $72(79 \%)$ & $123(85 \%)$ & $195(83 \%)$ \\
\hline Opinion polls or interviews & $39(43 \%)$ & $53(37 \%)$ & $92(39 \%)$ \\
\hline Other $^{\mathrm{d}}$ & $4(4 \%)$ & $13(9 \%)$ & $17(7 \%)$ \\
\hline \multicolumn{4}{|l|}{ Study phases in which partners were engaged ${ }^{\mathrm{a}}(n, \%)$} \\
\hline Research topics and/or research questions & $54(59 \%)$ & $90(63 \%)$ & $144(61 \%)$ \\
\hline Interventions and/or comparators & $62(68 \%)$ & $101(70 \%)$ & $163(69 \%)$ \\
\hline Outcomes and/or measurement & $71(78 \%)$ & $106(74 \%)$ & $177(75 \%)$ \\
\hline Other aspects of study design & $61(67 \%)$ & $94(65 \%)$ & $155(66 \%)$ \\
\hline Recruitment and/or retention & $53(58 \%)$ & $97(67 \%)$ & $150(64 \%)$ \\
\hline Data collection & $29(32 \%)$ & $64(44 \%)$ & $93(40 \%)$ \\
\hline Data analysis and/or results review & $34(37 \%)$ & $98(68 \%)$ & $132(56 \%)$ \\
\hline Dissemination & $24(26 \%)$ & $77(53 \%)$ & $101(43 \%)$ \\
\hline
\end{tabular}

${ }^{a}$ Not mutually exclusive

b Includes biostatisticians, case managers, clinical investigators, community health worker organizations, community-based organizations, community residents, dietitians, educational institutions, National Institutes of Health, nurses, professional organizations/societies, regulatory/compliance professionals, support group organizations, and technology advisors

c Asked only to those reporting patient or stakeholder partner research team members

"Includes "conference presentations", "conversations", "peer buddies", "pilot study participants", and "webinars"

using data from both investigators and their research partners. This quantity of rich information on the engagement experience from multiple perspectives is not available from any other research funder.

PCORI investigators reported engaging a greater number of different types of stakeholder communities in more phases of the project and through more active approaches (e.g., partner co-investigator) than has been previously documented in the literature. For example, Concannon et al. found that most projects in the published literature that reported involving research partners engaged with patients, about half engaged with clinicians, and a few involved other stakeholders [22]. In contrast, nearly all the PCORI reports in this sample indicated engagement with both patients and clinicians. Engagement with caregivers, patient and caregiver advocacy organizations, and health systems representatives occurred in more than half of the reports. Inclusion of these diverse perspectives in production of research evidence is unprecedented on this scale and presents the opportunity to learn about the ways in which such inclusion changes research process, research quality, and speed of uptake.

In the data reported here, investigators and partners recognized similar effects of partner engagement, including 
Table 4 Partner engagement activities-illustrative quotations by study phase ( $N=235$ investigator reports; $N=260$ partner reports)

\begin{tabular}{|c|c|c|c|c|}
\hline \multirow[b]{2}{*}{$\begin{array}{l}\text { Study phase } \\
\text { (\% providing open-ended } \\
\text { response) }\end{array}$} & \multicolumn{4}{|c|}{ Activities (\% of phase-specific responses describing theme) } \\
\hline & Shared personal perspectives & Provided guidance and feedback & Shared decision-making & $\begin{array}{l}\text { Participated directly in study } \\
\text { conduct }\end{array}$ \\
\hline $\begin{array}{l}\text { Researcher understanding of } \\
\text { patient and stakeholder needs } \\
\text { (Investigators: NA) } \\
\text { (Partners: } 71 \% \text { ) }\end{array}$ & $\begin{array}{l}\text { "[l] share life experiences regarding pain } \\
\text { management and techniques that work } \\
\text { for me to identify triggers that cause my } \\
\text { chronic pain." } \\
\text {-Patient/consumer } \\
\text { (Investigators: NA) } \\
\text { (Partners: } 51 \% \text { ) }\end{array}$ & $\begin{array}{l}\text { "[We] provided feedback on what we } \\
\text { found valuable, what makes us } \\
\text { comfortable...The researchers were } \\
\text { pleasantly surprised at how we felt about } \\
\text { things." } \\
\text {-Patient/consumer } \\
\text { (Investigators: NA) } \\
\text { (Partners: } 46 \%)\end{array}$ & $\begin{array}{l}\text { "The entire study is framed around } \\
\text { the hypothesis- which we helped } \\
\text { generate." } \\
\text {-Representative of community-based } \\
\text { organization } \\
\text { (Investigators: NA) } \\
\text { (Partners: 10\%) }\end{array}$ & NA \\
\hline $\begin{array}{l}\text { Research topics and/or research } \\
\text { questions } \\
\text { (Investigators: 58\%) } \\
\text { (Partners: } 29 \%\end{array}$ & $\begin{array}{l}\text { "I explained to the research team what } \\
\text { research questions matter to patients } \\
\text { with communication disorders." } \\
\text {-Subject matter expert } \\
\text { "Patients and caregivers clearly } \\
\text { expressed how usual stroke care is } \\
\text { failing to meet their needs and ability to } \\
\text { regain health and independence." } \\
\text {-Investigator } \\
\text { (Investigators: } 5 \%) \\
\text { (Partners: } 23 \% \text { ) }\end{array}$ & $\begin{array}{l}\text { "As the community representatives, we } \\
\text { provided insight on how to frame } \\
\text { questions more appropriately in regards } \\
\text { to cultural stigmas we have noted in our } \\
\text { work." } \\
\text {-Representative of patient, consumer, or } \\
\text { advocacy organization } \\
\text { "[We] suggested and reframed topics to } \\
\text { resonate with patients and } \\
\text { stakeholders." } \\
\text {-Patient/consumer } \\
\text { (Investigators: } 54 \% \text { ) } \\
\text { (Partners: } 56 \% \text { ) }\end{array}$ & $\begin{array}{l}\text { "[We] collaborated [with partners] on } \\
\text { the decision for the study specific } \\
\text { aims." } \\
\text {-Investigator } \\
\text { "[We] identified research topic and } \\
\text { research community." } \\
\text {-Representative of community-based } \\
\text { organization } \\
\text { (Investigators: } 32 \% \text { ) } \\
\text { (Partners: } 25 \% \text { ) }\end{array}$ & NA \\
\hline $\begin{array}{l}\text { Interventions and/or } \\
\text { comparators } \\
\\
\text { (Investigators: 94\%) } \\
\text { (Partners: 28\%) }\end{array}$ & 年 & $\begin{array}{l}\text { "Stakeholders provided extensive } \\
\text { feedback on content, delivery and } \\
\text { organization of the intervention } \\
\text { curriculum" } \\
\text {-Investigator } \\
\text { (Investigators: } 72 \%) \\
\text { (Partners: } 63 \%)\end{array}$ & $\begin{array}{l}\text { "Patients ...on the advisory team and } \\
\text { co-researchers are responsible and } \\
\text { have control of the intervention } \\
\text { design and assisted by [staff name] } \\
\text { and the consultant with input from } \\
\text { the larger research team." } \\
\text {-Investigator } \\
\text { "[We] helped to determine the } \\
\text { content needs for the modules." } \\
\text {-Representative of patient, consumer, } \\
\text { or advocacy organization } \\
\text { (Investigators: } 27 \%) \\
\text { (Partners: } 29 \% \text { ) }\end{array}$ & NA \\
\hline $\begin{array}{l}\text { Outcomes and/or measurement } \\
\text { (Investigators: } 28 \% \text { ) } \\
\text { (Partners: } 40 \%)\end{array}$ & NA & $\begin{array}{l}\text { "Task Force members provided } \\
\text { feedback... [on] how to adequately } \\
\text { balance participant burden with study } \\
\text { outcomes." } \\
\text {-Investigator } \\
\text { "[I] discussed my priorities with } \\
\text { researchers. They described how they } \\
\text { would measure those issues." } \\
\text { - Payer (public or private insurance) } \\
\text { (Investigators: } 72 \% \text { ) } \\
\text { (Partners: } 33 \% \text { ) }\end{array}$ & $\begin{array}{l}\text { "I helped to write survey questions, } \\
\text { clarified the best times in a case to } \\
\text { administer questionnaires, helped } \\
\text { define at risk groups of } \\
\text { patients...[decided on] language to } \\
\text { use in conveying terminal prognosis, } \\
\text { added questions about prior } \\
\text { traumatization and validated PTSD } \\
\text { questions to try to identify at risk } \\
\text { patients who might not fit the profile } \\
\text { of 'at risk' or vulnerable patients." } \\
\text {-Patient/consumer } \\
\text { (Investigators: } 23 \% \text { ) } \\
\text { (Partners: } 9 \% \text { ) }\end{array}$ & NA \\
\hline $\begin{array}{l}\text { Recruitment and/or retention } \\
\text { (Investigators: 82\%) } \\
\text { (Partners: } 20 \% \text { \& 33\%) }\end{array}$ & NA & $\begin{array}{l}\text { "Our stakeholders played a large role in } \\
\text { the creation of interview guides, consent } \\
\text { scripts and language to encourage study } \\
\text { participants to enroll in our study. Their } \\
\text { feedback enable us to better } \\
\text { communicate and explain the purpose of } \\
\text { our study to potential participants." } \\
\text {-Investigator } \\
\text { (Investigators: } 46 \%) \\
\text { (Partners: } 64 \% \& 27 \% \text { ) }\end{array}$ & $\begin{array}{l}\text { "[l] was key in drafting patient } \\
\text { materials to invite participation." } \\
\text {-Patient/ consumer } \\
\text { (Investigators: } 15 \%) \\
\text { (Partners: } 0 \% \text { \& } 14 \% \text { ) }\end{array}$ & $\begin{array}{l}\text { "[The patient advocacy group] } \\
\text { recruited, organized, and ran the } \\
\text { focus group discussions." } \\
\text {-Investigator } \\
\text { "I've been able to make phone calls } \\
\text { to and [have] spoken to patients } \\
\text { and I've been able to recruit } \\
\text { several Spanish speaking } \\
\text { participants." } \\
\text {-Caregiver/family member } \\
\text { (Investigators: 43\%) } \\
\text { (Partners: } 38 \% \text { \& 67\%) }\end{array}$ \\
\hline $\begin{array}{l}\text { Data collection } \\
\text { (Investigators: 54\%) } \\
\text { (Partners: 15\%) }\end{array}$ & NA & $\begin{array}{l}\text { "Patient feedback has been helpful in } \\
\text { knowing how to best deliver and collect } \\
\text { the data." } \\
\text {-Investigator } \\
\text { (Investigators: } 50 \% \text { ) } \\
\text { (Partners: } 24 \% \text { ) }\end{array}$ & $\begin{array}{l}\text { "The stakeholder groups played a key } \\
\text { role in the selection of endpoints that } \\
\text { would be most important to } \\
\text { patients." } \\
\text {-Investigator } \\
\text { Investigators: } 13 \%) \\
\text { (Partners: } 18 \% \text { ) }\end{array}$ & $\begin{array}{l}\text { "I] collected progress data and } \\
\text { evaluations from participants and } \\
\text { reviewed the raw data." } \\
\text {-Other type of partner (peer group } \\
\text { facilitator) } \\
\text { (Investigators: } 35 \%) \\
\text { (Partners: } 53 \% \text { ) }\end{array}$ \\
\hline $\begin{array}{l}\text { Data analysis and/or results } \\
\text { review } \\
\text { (Investigators: } 54 \% \text { ) } \\
\text { (Partners: } 32 \%)\end{array}$ & NA & $\begin{array}{l}\text { "Our patient partner is actively } \\
\text { contributing to the discussion of the } \\
\text { results." } \\
\text {-Investigator } \\
\text { (Investigators: } 53 \%) \\
\text { (Partners: } 71 \% \text { ) }\end{array}$ & $\begin{array}{l}\text { "Stakeholders did help refine our } \\
\text { study protocol and statistical analysis } \\
\text { plan." } \\
\text {-Investigator } \\
\text { (Investigators: 9\%) } \\
\text { (Partners: } 4 \% \text { ) }\end{array}$ & $\begin{array}{l}\text { "We reviewed a coding manual, a } \\
\text { qualitative coding document and a } \\
\text { quantitative coding document and } \\
\text { noted redundancies, made } \\
\text { suggestions for additions, changed } \\
\text { language to ensure capture of data } \\
\text { relevant to the concerns of } \\
\text { stakeholders." } \\
\text { - Patient/consumer } \\
\text { (Investigators: 40\%) } \\
\text { (Partners: } 36 \%)\end{array}$ \\
\hline
\end{tabular}


Table 4 continued

\begin{tabular}{|c|c|c|c|c|}
\hline $\begin{array}{l}\text { Dissemination } \\
\text { (Investigators: 51\%) } \\
\text { (Partners: 23\%) }\end{array}$ & $\begin{array}{l}\text { "[When disseminating results, I] bring } \\
\text { real life experiences from my personal } \\
\text { life and as well as from the multitude of } \\
\text { families I have worked with over the } \\
\text { years." } \\
\text {-Caregiver/family member } \\
\text { (Investigators: } 0 \%) \\
\text { (Partners: } 31 \% \text { ) }\end{array}$ & $\begin{array}{l}\text { "The stakeholder advisory panel provided } \\
\text { feedback and ideas on potential } \\
\text { dissemination channels for sharing the } \\
\text { final results of the longitudinal survey as } \\
\text { well as the survey instruments." } \\
\text {-Investigator } \\
\text { (Investigators: } 20 \% \text { ) } \\
\text { (Partners: } 38 \% \text { ) }\end{array}$ & $\begin{array}{l}\text { "The principal investigator and key } \\
\text { stakeholders have begun planning a } \\
\text { policy summit with the American } \\
\text { College of Surgeons to present study } \\
\text { findings. Over the course of these } \\
\text { planning calls, the study team has } \\
\text { engaged an interdisciplinary group of } \\
\text { acute care medical providers and } \\
\text { other stake holders including injury- } \\
\text { related policy groups, NIH } \\
\text { stakeholders, and other key } \\
\text { stakeholder groups." } \\
\text {-Investigator } \\
\text { (Investigators: } 21 \% \text { ) } \\
\text { (Partners: } 0 \% \text { ) }\end{array}$ & $\begin{array}{l}\text { "[The partners] have co-authored } \\
\text { presentations at professional } \\
\text { meetings, participated on panel } \\
\text { discussion at the professional } \\
\text { meeting, and co-author our first } \\
\text { manuscript." } \\
\text {-Investigator } \\
\text { (Investigators: } 57 \% \text { ) } \\
\text { (Partners: } 77 \% \text { ) }\end{array}$ \\
\hline
\end{tabular}

refinements to research questions, design, study processes, and outcomes selection. These effects may address historic challenges in clinical research that limit the value of research for its end-users [23] by increasing the relevance and importance of the research for those end-users. Both investigators and partners report that engagement aided recruitment and retention, particularly noteworthy given that failures in recruitment and retention are a major factor in clinical trial failure [24]. Improvements in data collection efforts are also noteworthy, and suggest engagement may enhance other strategies to reduce missing data [25]. The findings here reinforce findings from smaller samples that did not include the partner view [8, 26-30].

PCORI expects engagement to inform key aspects of its funded projects but not necessarily every phase of every project. The role of engagement for a given project depends on the project content and context, and goals and past work in that research area. More work is underway to identify optimal engagement models by understanding intensity (e.g., in the number of partner types, phases and methods of engagement,), as well as effects of engagement such as the number and type of outcomes selected for study, recruitment rates, time to study completion, and study quality.

Investigators reported that partners influence the way the team works together. The implications of this should be further explored given the reported challenges of fully including diverse partner types and managing different perspectives [31]. Investigators, particularly those in the second year, also noted that partners influence other projects beyond the PCORI project. More research is needed to determine whether the number of investigators reporting such influence grows as the PCORI projects progress beyond the second year. The investigator ratings of research partner influence suggest a shift from more transactional approaches to engagement (e.g., discrete, one-way interactions) to more relational approaches, and qualitative analyses will continue to aid full understanding. Longitudinal examination will permit capture of the potential for transforming programs of research, affecting researchers' career trajectories, and changing the culture of how research is conducted [16]. Understanding the challenges of research engagement and strategies for overcoming those challenges is also critical to supporting a culture of engaged research. Although a detailed analysis of challenges and facilitators of engagement is beyond the scope of this paper, both investigators and partners identify key challenges, such as barriers to scheduling and logistics, limits on engagement due to health problems, and difficulty identifying and fully involving diverse partners [31].

Across study phases, investigators report more partner engagement than do partners in this sample. This may be due to limited visibility responding partners have of the extent of partner engagement in the project, since partners are asked to report on their individual contributions and many are engaged in limited parts of the project, while investigators report on the collective contributions of all partners across the entire project. Further, partners have recognized a need for investigators to more frequently and clearly report back to partners the ways that their input has contributed to the study [31]. While the discrepancy may also reflect over-reporting by investigators, this possibility is mitigated by ongoing relationships between investigators and PCORI project officers.

While this study represents significant advancements in knowledge about engagement in research, several limitations exist. These self-report data require respondents to recall their experiences over the past year, and likely capture the most salient, but not all, effects of engagement. Furthermore, respondents, particularly investigators, may overestimate their positive experiences with engagement given that this information is reported to the research funder. Although similar themes were identified among investigators and partners, partner reports may underreport the impacts of engagement because some research teams are more effective than others at communicating with partners about the effects of their contributions. Furthermore, the partner views reported here may not represent all PCORI research partners; only a subset of projects have 


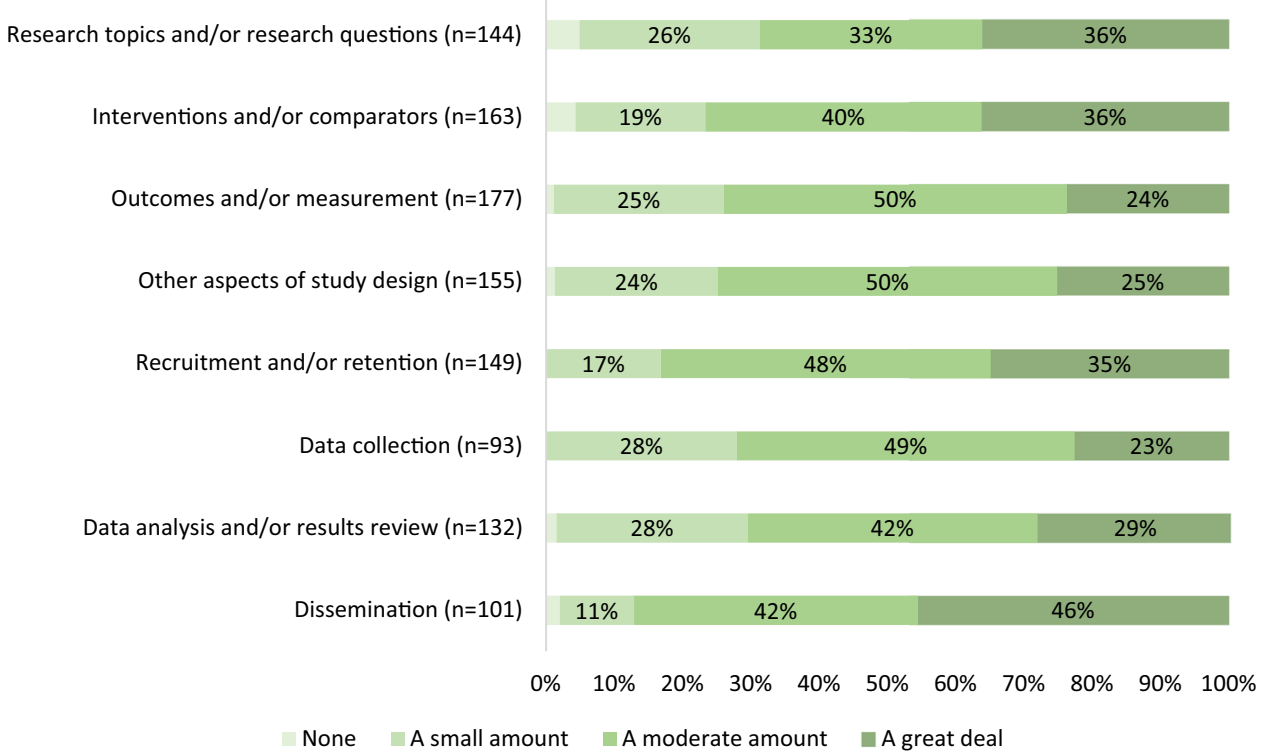

Fig. 3 Ratings of partner influence across study phases (investigator-reported)

partner respondents in the sample, and partners with more positive experiences may have been more likely to respond. The potential selection bias represents an important limitation to interpretation of partner report particularly. Further, the data were collected in English only, and the low proportion of Hispanic respondents suggests that the current sample may not fully represent all target study populations. Demographic differences between respondents and non-respondents are unknown. The data also do not yet include large enough sub-samples for meaningful comparison by stakeholder type. Additionally, although these items were refined through cognitive interviewing, additional measure refinement and item performance evaluation are needed. Self-report is an important source of information about engagement in research, but other complementary methods, including observational approaches, would enhance understanding and overcome limitations of selfreport. Moreover, findings may not generalize to studies funded by others under different requirements, in different contexts, and in other fields. Finally, data reported here are based on the first two years of funded projects. Some effects of engagement, such as impact on patient trust in findings, are not measurable until after project completion.

\section{Conclusion}

As PCORI projects mature towards dissemination and implementation of findings, the ultimate measure of the impact of engagement in research will be the usefulness of CER information, the use of that information in clinical decision making, and the impact on better health decisions, health care, and health outcomes, as noted in the PCORI Evaluation Framework. These current findings suggest that PCORI-funded projects are on the path towards desired impacts of engagement in research, with engagement of patients and other stakeholders as partners affecting research questions, design, processes, and outcome selection, as well as recruitment strategies and enrollment rates. Comparing results to the conceptual model of PCOR [16] shows that several hypothesized actions to facilitate PCOR are evident among the projects, including initiating and maintaining research partnerships, capturing and using partner perspectives, facilitating cross-communication with the research team (supported by open-ended feedback), and ensuring meaningful influence (supported by influence ratings) The near-term outcome of a culture of patientcenteredness is supported by the qualitative findings. Ongoing data collection should inform whether longerterm outcomes as specified in the conceptual model (Fig. 1) are realized and the extent to which specific intermediate outcomes specified in the evaluation framework (Fig. 2) are evident. Comparing results to the conceptual model of PCOR [16] shows that several hypothesized actions to facilitate PCOR are evident among the projects, including initiating and maintaining research partnerships, capturing and using partner perspectives, and facilitating cross-communication with the research team.

\section{Future directions}

Future examinations should explore how engagement affects PCORI's large, multi-site pragmatic clinical studies and other differences based on study type (e.g., 
Table 5 Effects of partner engagement-illustrative quotations by study phase ( $N=235$ investigator reports; $N=260$ partner reports)

\begin{tabular}{|c|c|c|}
\hline \multirow[b]{2}{*}{$\begin{array}{l}\text { Study phase } \\
\text { (\% providing open-ended } \\
\text { response) }\end{array}$} & \multicolumn{2}{|c|}{ Effects (\% of phase-specific responses describing theme) } \\
\hline & Enhanced patient-centeredness of study processes and outcomes & Enhanced study design, conduct, or efficiency \\
\hline $\begin{array}{l}\text { Researcher understanding of } \\
\text { patient and stakeholder needs } \\
\text { (Investigators: NA) } \\
\text { (Partners: } 70 \%)\end{array}$ & $\begin{array}{l}\text { "[Our engagement] helped prioritize the issues that are of concern to } \\
\text { constituents." } \\
\text {-Representative of patient, consumer, or advocacy organization } \\
\text { (Investigators: N/A) } \\
\text { (Partners: } 15 \%)\end{array}$ & $\begin{array}{l}\text { "With my professional background, my perspective toward patients offered a unique } \\
\text { view as to how to design the modules and how to meet [patients'] needs best." } \\
\text {-Representative of patient, consumer, or advocacy organization } \\
\text { (Investigators: N/A) } \\
\text { (Partners: } 40 \% \text { ) }\end{array}$ \\
\hline $\begin{array}{l}\text { Research topics and/or research } \\
\text { questions } \\
\text { (Investigators: } 24 \% \text { ) } \\
\text { (Partners: } 27 \% \text { ) }\end{array}$ & $\begin{array}{l}\text { "Our decision to pursue this study and, in particular, the patient } \\
\text { population...was driven by requests from patients and providers who noted a } \\
\text { clear gap in knowledge and absence of treatment guidelines for this distinct } \\
\text { patient group." } \\
\text {-Investigator } \\
\text { (Investigators: } 26 \%) \\
\text { (Partners: } 11 \%)\end{array}$ & $\begin{array}{l}\text { "Patient input was used to refine the research questions and outcomes to be } \\
\text { explored." } \\
\text {-Investigator } \\
\text { (Investigators: } 26 \%) \\
\text { (Partners: } 37 \%)\end{array}$ \\
\hline $\begin{array}{l}\text { Interventions and/or } \\
\text { comparators } \\
\text { (Investigators: } 51 \% \text { ) } \\
\text { (Partners: } 25 \%)\end{array}$ & $\begin{array}{l}\text { "Program [is now] designed to fit [the] culture." } \\
\text {-Representative of community-based organization } \\
\text { "As members of the research team, patient stakeholders were key to the } \\
\text { development of the survivorship care plan tool (intervention) and measures of } \\
\text { effectiveness. Their involvement has ensured a truly patient-centered tool and } \\
\text { relevance of potential findings to the patient audience." } \\
\text {-Investigator } \\
\text { (Investigators: } 33 \%) \\
\text { (Partners: } 33 \%)\end{array}$ & $\begin{array}{l}\text { "Patients helped design the intervention through information provided in focus } \\
\text { groups and interviews and stakeholders helped refine and finalize the intervention } \\
\text { manual by reviewing and making suggested changes to language and content." } \\
\text {-Investigator } \\
\text { "Clinician input has been very helpful in designing the implementation of the } \\
\text { intervention" } \\
\text {-Investigator } \\
\text { (Investigators: } 51 \%) \\
\text { (Partners: } 55 \%)\end{array}$ \\
\hline $\begin{array}{l}\text { (Investigators: 39\%) } \\
\text { (Partners: } 37 \% \text { ) }\end{array}$ & $\begin{array}{l}\text { "[Partner] input resulted in our primary medical outcome being disability days } \\
\text { at one year after treatment." } \\
\text {-Investigator } \\
\text { "Additional outcomes (blood pressure change, weight loss, hospitalization, and } \\
\text { sleepiness during driving) were added before the start of the study by } \\
\text { policymakers in the patient-stakeholder engagement panel." } \\
\text {-Investigator } \\
\text { (Investigators: } 24 \%) \\
\text { (Partners: } 20 \%)\end{array}$ & $\begin{array}{l}\text { "In direct response to stakeholder feedback, we limited the number of questions and } \\
\text { redundancy across measures." } \\
\text {-Investigator } \\
\text { (Investigators: } 53 \% \text { ) } \\
\text { (Partners: } 20 \% \text { ) }\end{array}$ \\
\hline $\begin{array}{l}\text { Recruitment and/or retention } \\
\text { (Investigators: } 41 \% \text { ) } \\
\text { (Partners: } 20 \% \& 30 \% \text { ) }\end{array}$ & $\begin{array}{l}\text { "[We] informed researchers how difficult obtaining a family's participation in } \\
\text { the study at three months post onset would be. Families are [usually] going } \\
\text { through an extraordinarily difficult time and are not ready to emotionally grasp, } \\
\text { or commit valuable time to study participation so close to the diagnosis." } \\
\text {-Caregiver/family member } \\
\text { "[We] changed the language to make it easier for the patient and family to } \\
\text { understand what they were agreeing to." } \\
\text {-Patient/consumer } \\
\text { "As our patient population consists of children, the parents/guardians were } \\
\text { very helpful. They described their experiences of being recruited into a study } \\
\text { as well as the experiences of being parents in general. This helped us } \\
\text { tremendously on how to approach families as well as taking into consideration } \\
\text { their busy lives and how follow-up surveys and phone calls would fit into that." } \\
\text {-Investigator } \\
\text { (Investigators: } 37 \% \text { ) } \\
\text { (Partners: } 0 \% \& 13 \% \text { ) }\end{array}$ & $\begin{array}{l}\text { "[Partners] helped strategize when [we] encountered poor recruitment... [They] } \\
\text { reviewed options for adding sites, refining eligibility criteria... [They] helped } \\
\text { navigate logistical challenges of recruiting patients in a busy primary care setting." } \\
\text {-Investigator } \\
\text { "We were advised [by our partners] to send the participants regular emails in addition } \\
\text { to providing the gift cards at the time of their clinic visit. ... Follow-up } \\
\text { questionnaires are now sent to study participants via email ... with excellent response } \\
\text { rates." } \\
\text {-Investigator } \\
\text { "We brainstormed ways to change their approach so that families are more at } \\
\text { ease...they changed how they reach out to patients based on our feedback. We } \\
\text { discussed why families might choose to withdraw from the study and...about better } \\
\text { ways to communicate with families that are involved in the study. [As a result] more } \\
\text { families stayed in the study." } \\
\text {-Caregiver/family member } \\
\text { (Investigators: } 61 \%) \\
\text { (Partners: } 61 \% \text { \& } 54 \% \text { ) }\end{array}$ \\
\hline $\begin{array}{l}\text { Data collection } \\
\text { (Investigators: 26\%) } \\
\text { (Partners: } 12 \% \text { ) }\end{array}$ & $\begin{array}{l}\text { "Allowed the group to be more sensitive about collecting data from Black men } \\
\text { who sometimes shy away from providing their personal information." } \\
\text {-Subject matter expert } \\
\text { "Based on stakeholder advice, we added additional community sites that were } \\
\text { more accessible for families to attend the baseline appointments, as well as } \\
\text { being available } 7 \text { days a week to accommodate families' work schedules. This } \\
\text { change was particularly impactful for our Hispanic/Latino participants, some of } \\
\text { whom needed to complete baseline data collection over several appointments, } \\
\text { through interview rather than paper survey, or via follow-up phone calls." } \\
\text {-Investigator } \\
\text { (Investigators: } 24 \%) \\
\text { (Partners: } 72 \%)\end{array}$ & $\begin{array}{l}\text { "Clinicians and clinic staff gave input...to minimize effect on clinic flow and } \\
\text { maximize research efficiency." } \\
\text {-Investigator } \\
\text { "The engagement of stakeholders has profoundly affected data collection in our } \\
\text { study. We are very proud to have }>90 \% \text { survey completion for our surveys collected } \\
\text { six months after trial enrollment.... Overall, the suggestions made by our advisory } \\
\text { boards in this area have greatly influenced follow-up data collection processes, and } \\
\text { has contributed to the successful collection of both survey and [health condition] } \\
\text { data." } \\
\text {-Investigator } \\
\text { (Investigators: } 68 \%) \\
\text { (Partners: } 31 \%)\end{array}$ \\
\hline $\begin{array}{l}\text { Data analysis and/or results } \\
\text { review } \\
\text { (Investigators: } 7 \% \text { ) } \\
\text { (Partners: } 28 \% \text { ) }\end{array}$ & NA & $\begin{array}{l}\text { "Stakeholders review results, offer interpretations, challenge researchers' } \\
\text { assumptions, and suggest additional analyses." } \\
\text {-Investigator } \\
\text { "[We were] able to determine if the results were enough to help us make an informed } \\
\text { decision and add additional information." } \\
\text {-Caregiver/family member } \\
\text { (Investigators: } 81 \% \text { ) } \\
\text { (Partners: } 34 \%)\end{array}$ \\
\hline
\end{tabular}


Table 5 continued

\begin{tabular}{|l|l|l|}
\hline & $\begin{array}{l}\text { "Stakeholders can be presenters too. [We] helped reach lay people as well as } \\
\text { medical professionals." } \\
\text {-Caregiver/family member }\end{array}$ & $\begin{array}{l}\text { "[Partner engagement in dissemination] builds capacity in patient partners, } \\
\text { increases credibility of research, [and] serves as an example of shared power } \\
\text { for other researchers in the audience." } \\
\text {-Investigator }\end{array}$ \\
$\begin{array}{ll}\text { Dissemination } \\
\text { (Investigators: } 11 \%)\end{array}$ & $\begin{array}{l}\text { "The questions I get asked after presenting is invigorating, because people are } \\
\text { paying attention and getting something from the study and my experiences." } \\
\text {-Representative of patient, consumer, or advocacy organization }\end{array}$ & $\begin{array}{l}\text { (Investigators: } 56 \%) \\
\text { (Partners: } 47 \%) \\
\text { in changing physician practices and content important to share with patients." } \\
\text {-Investigator }\end{array}$ \\
& $\begin{array}{l}\text { (Investigators: } 52 \%) \\
\text { (Partners: } 25 \%)\end{array}$ & \\
\hline
\end{tabular}

interventional vs. observational, treatment comparisons vs. health system comparisons) and population (e.g., for hard to reach populations). Future research is needed to understand the unintended consequences of engagement (e.g., on project budget and timeline) and how to mitigate them, as well as other effects of engagement in research hypothesized in the conceptual model [16], including the effects on partners, investigators, and their institutions in pursuit of establishing a culture of patient-centeredness in research.

Several longer-term questions remain to be addressed as the PCORI-funded projects are completed. The extent of concordance, and causes of any discordance, in views between investigators and research partners bears examination, particularly as such concordance may vary by type of study and engagement approach. Additionally, overcoming the potential selection bias in research partner report requires outreach to more research partners and PCORI is exploring ways to obtain a wider range of perspectives on research engagement from the engaged research partners. Further, understanding differences in the effects of engagement by partner type could ultimately inform strategies for how to engage with different stakeholder communities at various parts of the research process.

The evaluation framework and conceptual model that guide this work are applicable to research in which health care stakeholders are actively engaged. They can guide collection of data beyond PCORI and provide a foundation for the accumulating evidence about engagement in research, providing a means to improve the efficiency and effectiveness of engagement itself. As the evidence base about research engagement expands, the role of engagement in research in improving public health must be reexamined, to support the incorporation of new knowledge into practice through a feedback loop from theory to research and back.

Acknowledgements PCORI thanks the investigators and research partners who have contributed to the data collected in this report. The authors also gratefully acknowledge Emily Elstad, PhD; Heather Ma; Andrew Amolegbe, MPH; and Tsion Ghedamu from the American
Institutes for Research and Ray Maietta, PhD; Jeff Petruzzelli; and Lucinda Hudson, PhD from Research Talk for their contributions to the qualitative analysis of open-ended responses; Alan Carr, $\mathrm{PhD}$ and Corina Owens, $\mathrm{PhD}$ for their quantitative analysis of the closed-ended items, as well as other PCORI staff contributing to the collection and analysis of these data, including Lauren Fayish, MPH; Ninma Fearon, MPH; Kellie Hall, BA; Rachel Hemphill, PhD; and Beth Nguyen, $\mathrm{MPH}$.

Open Access This article is distributed under the terms of the Creative Commons Attribution 4.0 International License (http://crea tivecommons.org/licenses/by/4.0/), which permits unrestricted use, distribution, and reproduction in any medium, provided you give appropriate credit to the original author(s) and the source, provide a link to the Creative Commons license, and indicate if changes were made.

\section{References}

1. Reeve, B. B., Wyrwich, K. W., Wu, A. W., Velikova, G., Terwee, C. B., Snyder, C. F., et al. (2013). ISOQOL recommends minimum standards for patient-reported outcome measures used in patient-centered outcomes and comparative effectiveness research. Quality of Life Research, 22(8), 1889-1905.

2. Kirwan, J. R., \& Hewlett, S. (2007). Patient perspective: Reasons and methods for measuring fatigue in rheumatoid arthritis. Journal of Rheumatology, 34(5), 1171-1173.

3. Food and Drug Administration (FDA). (2009). Guidance for industry on patient-reported outcome measures: Use in medical product development to support labeling claims, federal register (Vol. 74, pp. 65132-65133). Washington, DC: U.S. Department of Health and Human Services.

4. Charlton, J. I. (1998). Nothing about us without us: Disability oppression and empowerment. Berkeley: University of California Press.

5. Viswanathan, M., Ammerman, A., Eng, E., Garlehner, G., Lohr, K. N., Griffith, D., Rhodes, S., Samuel-Hodge, C., Maty, S., Lux, L., Webb, L., Sutton, S. F., Swinson, T., Jackman, A., \& Whitener, L. (2004). Community-based participatory research: Assessing the evidence. Evidence Report Technology Assessment (Summ)(99), 1-8.

6. Jones, M. M., Kamenetzky, A., Manville, C., Ghiga, I., MacLure, C., Harte, E., et al. (2016). The National Institute for Health Research at 10 Years. Arlington, VA: RAND Corporation.

7. Canadian Institutes of Health Research. (2011). Canada's strategy for patient-oriented research. Ottawa, Ontario. Retrieved March 16, 2017 from https://www.cihr-irsc.gc.ca/e/documents/P-O_ Research_Strategy-eng.pdf. 
8. Staley, K. (2009). Exploring impact: Public involvement in NHS, public health and social care research. Eastleigh: INVOLVE.

9. Ring, L. (2016, July). EMA review and qualification process. Paper presented at the ISOQOL Measuring What Matters Symposium, Washington, DC.

10. Innovative Medicines Initiative. European Patients' Academy on Therapeutic Innovation. Retrieved March 17, 2017, from https:// www.imi.europa.eu/content/eupati.

11. Rich, E. C. (2016). From concept to policy: 10 years after the call for a US center for comparative effectiveness information. Journal of Comparative Effectiveness Research, 6, 9-11.

12. Postmus, D., Mavris, M., Hillege, H. L., Salmonson, T., Ryll, B., Plate, A., et al. (2016). Incorporating patient preferences into drug development and regulatory decision making: Results from a quantitative pilot study with cancer patients, carers, and regulators. Clinical Pharmacology and Therapeutics, 99(5), 548-554.

13. Canadian Institutes of Health Research. (2015). Health research roadmap II: Capturing innovation to produce better health and health care for canadians strategic plan 2014-15 to 2018-19. Retrieved March 16, 2017 from http://www.cihr-irsc.gc.ca/e/ 48964.html\#a7.

14. National Institutes for Health Research. (2016). Going the Extra Mile. Paper presented at the Patient and Public Involvement NIHR Impact Workshop.

15. Dudley, L., Gamble, C., Preston, J., Buck, D., The EPIC Patient Advisory Group, Hanley, B., et al. (2015). What difference does patient and public involvement make and what are its pathways to impact? Qualitative study of patients and researchers from a cohort of randomised clinical trials. PLOS ONE, 10(6), e0128817.

16. Frank, L., Forsythe, L., Ellis, L., Schrandt, S., Sheridan, S., Gerson, J., et al. (2015). Conceptual and practical foundations of patient engagement in research at the patient-centered outcomes research institute. Quality of Life Research, 24(5), 1033-1041.

17. Patient-Centered Outcomes Research Institute (PCORI). (2015). Patient-Centered Outcomes Research Institute (PCORI) Evaluation Framework 2.0. Retrieved March 17, 2017 from http://www. pcori.org/sites/default/files/PCORI-Evaluation-Framework-2.0. pdf.

18. Forsythe, L. P., Frank, L., Walker, K. O., Anise, A., Wegener, N., Weisman, H., et al. (2015). Patient and clinician views on comparative effectiveness research and engagement in research. Journal of Comparative Effectiveness Research, 4(1), 11-25.

19. Vaismoradi, M., Turunen, H., \& Bondas, T. (2013). Content analysis and thematic analysis: Implications for conducting a qualitative descriptive study. Nursing \& Health Sciences, 15(3), 398-405.

20. Guest, G., MacQueen, Kathleen M., \& Emily, E. (2012). Applied thematic analysis. Thousand Oaks, California: Sage Publications Inc.
21. Sandelowski, M. (2001). Real qualitative researchers do not count: the use of numbers in qualitative research. Research in Nursing \& Health, 24(3), 230-240.

22. Concannon, T. W., Fuster, M., Saunders, T., Patel, K., Wong, J. B., Leslie, L. K., et al. (2014). A Systematic review of stakeholder engagement in comparative effectiveness and patientcentered outcomes research. Journal of General Internal Medicine, 29(12), 1692-1701.

23. Moher, D., Glasziou, P., Chalmers, I., Nasser, M., Bossuyt, P. M., Korevaar, D. A., et al. (2016). Increasing value and reducing waste in biomedical research: who's listening? Lancet, 387(10027), 1573-1586.

24. Kasenda, B., von Elm, E., You, J., Blumle, A., Tomonaga, Y., Saccilotto, R., et al. (2014). Prevalence, characteristics, and publication of discontinued randomized trials. JAMA, 311(10), $1045-1051$.

25. Mercieca-Bebber, R., Palmer, M. J., Brundage, M., Calvert, M., Stockler, M. R., \& King, M. T. (2016). Design, implementation and reporting strategies to reduce the instance and impact of missing patient-reported outcome data: A systematic review. Quality of Life Research, 24(6), 81.

26. Brett, J., Staniszewska, S., Mockford, C., Herron-Marx, S., Hughes, J., Tysall, C., et al. (2014). Mapping the impact of patient and public involvement on health and social care research: A systematic review. Health Expectations, 17(5), 637-650.

27. Domecq, J. P., Prutsky, G., Elraiyah, T., Wang, Z., Nabhan, M., Shippee, N., et al. (2014). Patient engagement in research: A systematic review. BMC Health Services Research, 14, 89.

28. Forsythe, L. P., Ellis, L. E., Edmundson, L., Sabharwal, R., Rein, A., Konopka, K., et al. (2016). Patient and stakeholder engagement in the PCORI pilot projects: Description and lessons learned. Journal of General Internal Medicine, 31(1), 13-21.

29. Forsythe, L. P., Szydlowski, V., Murad, M. H., Ip, S., Wang, Z., Elraiyah, T. A., et al. (2014). A systematic review of approaches for engaging patients for research on rare diseases. Journal of General Internal Medicine, 29(Suppl 3), S788-S800.

30. Shippee, N. D., Domecq Garces, J. P., Prutsky Lopez, G. J., Wang, Z., Elraiyah, T. A., Nabhan, M., et al. (2015). Patient and service user engagement in research: a systematic review and synthesized framework. Health Expectations, 18(5), 1151-1166.

31. Forsythe, L., Anyanwu, C., Schneider, M., Brentzel, F., Kohler, P., Ritok, M., et al. (2016). Patient and stakeholder engagement in research: Identifying challenges and developing solutions. National Harbor, Maryland: PCORI Second Annual Meeting. 